Goldschmidt 2021 Abstract

https://doi.org/10.7185/gold2021.7355

\section{Thermal analyses of biocarbonates as part of the search for traces of life on Mars}

\author{
ALEXANDRA MARIE, ELSA PERRON ${ }^{1}$, FABIEN \\ STALPORT $^{2}$, ALEXANDRE CHEVILLOT-BIRAUD ${ }^{3}$, \\ SYLVIE DERENNE ${ }^{4}$, CHRISTELLE ANQUETIL ${ }^{4}$, STEPHAN \\ BORENSZTAJN $^{1}$, SOPHIE NOWAK ${ }^{5}$, PIERRE BÜRCKEL ${ }^{1}$, \\ LÉNA LECOURT ${ }^{1}$ AND BENEDICTE MENEZ ${ }^{1}$ \\ ${ }^{1}$ Université de Paris, Institut de physique du globe de Paris, \\ CNRS UMR 7154 \\ ${ }^{2}$ Université de Paris, Laboratoire Interuniversitaire des Systèmes \\ Atmosphériques, CNRS UMR 7583 \\ ${ }^{3}$ Université de Paris, Laboratoire Interfaces Traitements \\ Organisation et DYnamique des Systèmes, CNRS UMR 7086 \\ ${ }^{4}$ Sorbonne Université, Milieux environnementaux, transferts et \\ interactions dans les hydrosystèmes et les sols, UMR 7619 \\ METIS \\ ${ }^{5}$ Université de Paris, Plateforme RX, UFR Chimie \\ Presenting Author: perron@ipgp.fr
}

The search for organic compounds on Mars is currently the main strategy to highlight a potential extinct or extant life on this planet. However, the environmental conditions on the surface of Mars (e.g. radiations, high level of oxidants) can lead to their degradation [1]. An alternative method to detect clues of life is to search for the presence of biominerals, probably more resistant in such an environment. The objective is therefore to be able to distinguish bio- and organo-minerals from their abiotic counterparts by using instruments that can carry out in situ measurements on Mars. Differential thermal analysis (DTA) coupled with gas chromatography and mass spectrometry (GCMS) share similarities with space instruments dedicated to in situ analyses on Mars, such as SAM (Sample Analysis at Mars) aboard the rover Curiosity or MOMA (Mars Organics Molecule Analyser) from the ExoMars 2022 mission; Both instruments are gas chromatographs coupled to mass spectrometers.

Several space missions revealed the presence of carbonates at the surface of Mars [2]. Carbonates are abundant minerals in the Earth's rock record that were mostly formed by biological activity, both through biologically controlled mineralization and biologically induced mineralization. DTA analyses show differences of more than $20^{\circ} \mathrm{C}$ in phase transition temperatures between abiotic $\mathrm{Mg}$ - and $\mathrm{Ca}$-carbonates and natural biogenic carbonates formed in various contexts (including ancient and modern stromatolites, alkaline hydrothermal vents) as well as laboratory carbonates formed by carbonatogen microbial strains and organomineralization. Additional analyses by pyrolysis-GCMS reveal in biocarbonates a wide variety of organic fragments characteristic of organic matter with a biological origin. Thus, DTA-GC-MS would have the potential to discriminate biocarbonates from abiotic carbonates and would lead to a better understanding of the physico-chemical properties of these minerals. This approach may eventually be used for the search for possible records of life on Mars involving the MOMA instrument.
[1] O. Poch, S. Kaci, F. Stalport, et al. (2014), Icarus 242, 5063.

[2] R. V. Morris, B. C. Clark, D. C. Golden, et al. (2010), Science 329.5990, 421-424.

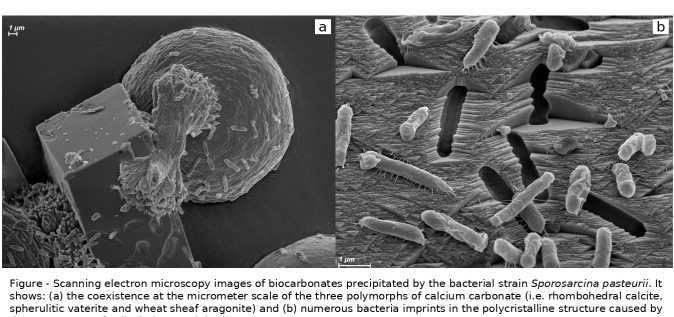

